\title{
Analyzing Speech Acts In The Pakistani Social Media Scenario: A Gender-Based Comparison
}

\author{
Anmol Ahmad \\ Department of Humanities \\ COMSATS Institute of Information Technology, Islamabad
}

Fizza Farrukh

Department of Humanities

Air University, Islamabad

\begin{abstract}
Gender studies have been an invigorating field of study under numerous lenses. Such explorations explore the inimitable distinctiveness and resemblance between the two genders. Correspondingly, this study focuses particularly on written communication of Pakistanis. Utilizing Searle's Taxonomy for Speech Acts (1969) and Wulandari (2014)'s Taxonomy for Speech Act Functions, this research investigates differences and similarities of language use among Males and Females on the online social platforms of Facebook and Twitter. Data comprises of a thousand utterances accounted from selected social mediums. Results reveal Pakistani Males tend to use Expressive Acts often within their language while updating their status messages on Facebook and Twitter; contrastingly, Pakistani Females prefer to employ the Directive and Assertive Acts frequently in their language used in Facebook and Twitter status updates. Furthermore, Pakistani Males utilize the medium for informing their potential audience about various topics. While, Pakistani Females make use of the status messages to achieve multiple purposes, including: informing, suggesting and asserting. Through application of ANOVA, study's results validate linguistic differences in language use of Pakistani Males and Females. It corroborates the fact that gender-based differences are part of the identity of a person and these are reflected through the medium of language elaborately.
\end{abstract}

Keywords: Speech Acts, Social Media, Gender Study, Language Use, Communicative Functions.

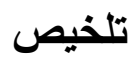

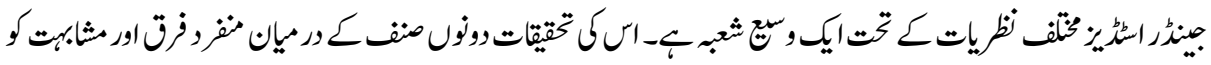

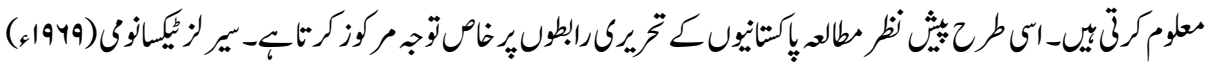

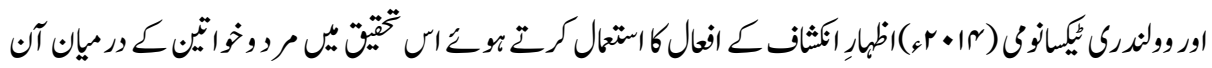

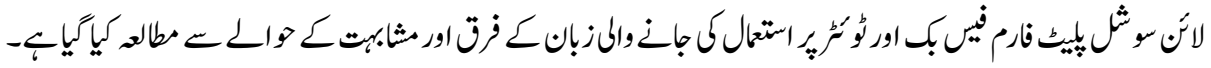

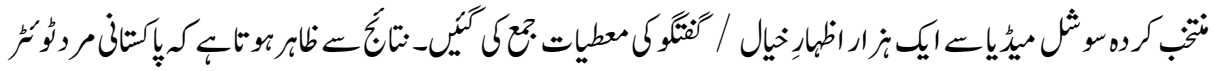

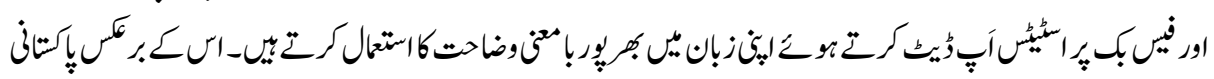




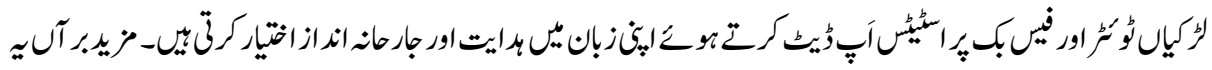

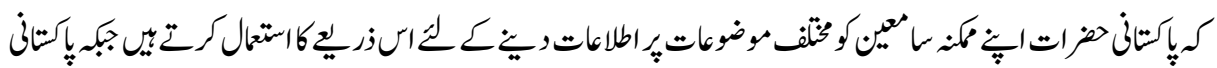

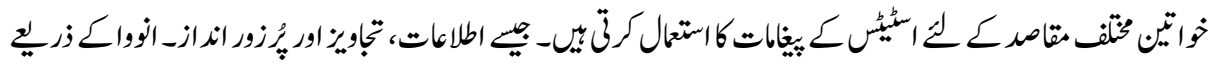

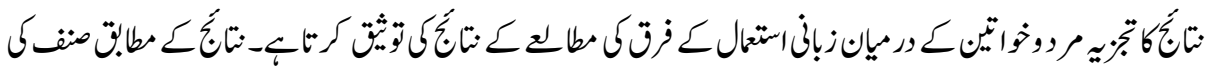

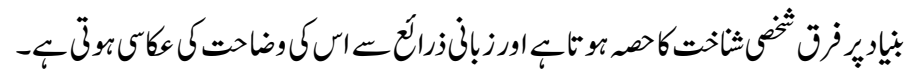

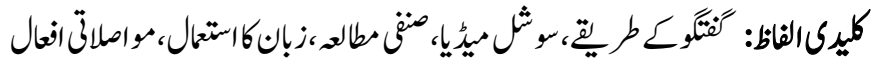

\section{Introduction}

Humans' mediums of communication have changed with the passage of time. Now, communication does not mean that humans always meet face-to-face with the other people to converse. They may interact with each other without having to meet. Facebook and Twitter are two such popular online social networking websites, which provide a virtual platform for the masses to converse, negotiate their identities, use various linguistic repertoires and strategies, encode and decode messages, share opinions and express their emotions in multidimensional ways via language use. Understanding this complex process is one of the motives which instilled the current study on social media users' language.

According to Crystal (2000, p. 212) language is a vital instrument for human communication. It means that language is systematic, and makes conventional use of sound signs or written symbols for interaction and self expression. Within this gigantic world of language use, it is important to narrow down to a particular unit of analysis. This study delimits itself to exploration of Pakistani Social Media users' use of Speech acts and Communicative Functions in their language. Deciphering speech acts, through a critical analysis, can unearth the actual intent of the writer/speaker (Singh, 1991). According to Kreidler (1998:26) an action through utterance is called as a speech act. Furthermore, he stated that an utterance is "an act of speech or writing; it is a specific event at a particular time and place and involving at least one person, the one who produces the utterance, but usually more than one person". Thus, speech acts can more specifically include linguistic actions such as complaint, argument, invitation, apology, promise or compliment.

Moreover, an utterance (particularly on the social media) is made voluntarily and is properly planned by the writer to achieve a particular goal and to communicate a particular feeling towards his/her potential readers (Vladutescu, 2015). The utterance which takes place in such a way, involves certain communicative functions, while it is being produced 
by the author. This functionality can only be deciphered by critically analyzing the semantics of the words, phrases and the context of that particular utterance. Hence, the current study aims to address both speech acts and communicative functions to provide a multifaceted output regarding the language used in the Pakistani Social Media scenario.

For a further deep understanding of the subject matter, gender differences, in terms of language use, formulate the basis for this research. To what extent is the language of males and females different or similar is a question that has been constantly interrogated by scholars (Newman et al., 2008). Since language is seen as a reflection of identity, it has been estimated to be helpful in deciphering and understanding how men and women utilize the tool of language. Furthermore, it is imperative to comprehend these genderbased distinctions for realizing the uniqueness which each gender has. Hence, the current study attempted to comprehend the language use - its differences and similarities between the Pakistani males and females on social media, in order to grasp their distinctive identities.

\section{Assumption of the Study}

There is a visible difference among the speech acts being used by Pakistani males and females on the social media.

\section{Research Questions}

This study attempts to answer the following questions:

1. What types of speech acts are being used by Pakistani males and females on the social media websites, Facebook and Twitter?

2. Which speech act(s) is / are most frequently occurring among the Pakistani males and females over the social media websites, Facebook and Twitter?

3. What are the similarities and differences in the use of Speech Acts by the Pakistani males and females on the social media websites, Facebook and Twitter?

4. What are the communicative functions of the Speech acts used by the Pakistani males and females on the social media websites, Facebook and Twitter?

\section{Objectives of the Study}

The aims of this study include the following:

1. To explore the use of language in context by Pakistanis on the social networking websites of Facebook and Twitter.

2. To study communicative functions which emerge from the analysis of the status updates by the Pakistanis. 
3. To decipher the similarities and differences in language use by the Pakistani males and females on the social networking websites, Facebook and Twitter.

\section{Significance of the Study}

This particular research study aids to understand how people use social media to express their personal experience, emotion, feelings. Moreover, it helps explore the various linguistics trends and repertoires being used by the Pakistani social media community in particular. Furthermore, it provides an overall idea on how the Pakistani people update regarding their day to day activities, share their experiences, their reaction to every day issues and, ultimately, discuss anything which affects them.

\section{Delimitation}

The study is delimited to a random set of data only. Population of this study included all Pakistani males and females who use Facebook and Twitter which amounts to more than 7 million users combined, according to the Statistics by Social Bakers (2012a; 2012b). Utilizing the formulae for Sample Size Determination, a minimum of 600 samples was needed to produce reliable results for the study. To generate elaborate results, the research sampled 1000 status updates and delimited the study to them. The technique of purposive sampling and random sampling were used to select 500 Facebook Status Updates and 500 Twitter Status Updates of Pakistani Males and Females, respectively. Furthermore, random sampling was conducted so that the collected data could be generalized for the whole population of Pakistani people using social media as a mode of communication.

\section{Literature Review}

This section aims to connect the basic terminologies of the aforementioned topic and explain their relative importance in relation with the society and people. Furthermore, the study intends to highlight the niche developed for the current study within the pool of previous studies related with speech act analysis in particular.

\section{Speech Acts: An Introduction}

The notion of Speech Act and its theory was initiated by Austin (1962) and further developed by Searle (1969). Basically, Speech Act implies to utter a statement which is equivalent to performing an action. Every speech act, once uttered, changes the context amid the speaker and the listener. For instance, common speech acts include promising, inviting, welcoming, thanking, congratulating etc. This impact of Speech Acts makes them viable for studying and deciphering the intentions of the speakers hidden under the 
communicated message. Thus, Searle (1969) rightly remarks that, within this field, the concern of linguistic analysis revolves around the speaker's and the hearer's capability to manage, create and decode the meaning of words that they have uttered for communiqué.

If somebody uses language for explaining their sentiments or starting a debate or even for degrading somebody - all of it falls under the category of Speech Acts (Illyas \& Khushi, 2012). Furthermore, Sadock (2009) briefly explains the speech acts that they are those actions which are done through the medium of speaking.

Speech act investigations have taken numerous structures and have been connected to numerous circumstances. Henceforth, it appears relevant to consider how messages are developed in various mediums to understand how individuals communicate and make their opinions significant through language.

\section{Analyzing Speech Acts}

The presence of the speaker and the hearer is a compulsory necessity for the conduction of any kind of speech act in the world (Das, 2005). Furthermore, once the message is delivered from the addresser to the addressee, it is left upon the addressee to decode the point and respond accordingly. While investigating these particular utterances, research scholars (Das 2005; Sadock, 2009) suggest that the following three things need to be observed:

1. The language use within that utterance

2. The intent of the interlocutor

3. The social context in which the interaction took place.

Moreover, according to Sadock (2009), during the process of communication, three different kinds of speech acts can be possibly produced:

i. Locutionary act: It implies that those particular sounds, which are uttered out of a speakers' mouth comprise of certain identifiable features which the listener can understand. Not only this, but those sounds have particular reference points too, that is, they are not randomly uttered by the speaker.

ii. Illocutionary act: This emphasizes the intention of the speaker, who is delivering the utterance to the hearer. For example, if a person at a restaurant asks about his order 'Is the dish ready yet?', his basic aim is not to seek information about the dish, rather his intention is to convey the fact to the waiter that he is hungry and is anxiously waiting for the dish to be served, and, furthermore, he implicitly demands the waiter to bring it as soon as possible in an indirect manner. Moreover, the illocutionary acts can be guided by particular cultural norms as well. Its range and tendency for acceptance in a society, varies from culture to culture.

iii. Perlocutionary act: This basically points towards the psychological effect a particular utterance can have on a hearer (Holtgraves, 2002, p. 10-11). This is also 
a significant factor which will be studied in the present research as well. It particularly pertains to the function of the particular utterance.

\section{Searle's Speech Act Taxonomy (1969)}

The theory presented by Searle (1969) utilizes the illocutionary purpose of the speech acts specifically. It addresses classes of expressions, each with a particular open reason and every arrangement thoroughly discrete from others. Searle (1969) explained five categories of speech acts: assertive, directives, commissives, expressions and declarations. The taxonomy, which he presented based on his theory, helps to illuminate the context, the speaker's psychological state, the intention and how the utterance conveys meaning to the intended audience.

For the current research the taxonomy presented by Searle (1969) will be used because it is comprehensive. Thus, according to Searle, there are five categories of speech acts, which have been explained below:

(i) Assertive acts: It explains a particular notion, belief or a proposition. If a person asserts, concludes, predicts, informs or reports then it will be termed as an assertive act. For example:

1. 'The earth is flat.'

2. 'The name of our country is Pakistan.'

(ii) Directive acts: Such acts are employed when the hearer has to be asked to do something. For example, if somebody is ordering, requesting, suggesting, or commanding then it falls within the Directive act (Holtgraves, 2002).

For example: 'Pass the salt!', 'I order you to leave school immediately.'

(iii) Commissive Acts: This act is used to commit something (Cutting, 2002). It can be in the form of promising.

For example: 'I will give you my address tomorrow.', 'I promised to tell him truth.'

(iv) Expressive Acts: These acts are used to express something. To express emotions or feelings etc, those which can be said as happy, sad, and angry etc. For example: 'Thank you for telling the truth!', 'I apologize, please forgive me!'

(v) Declarative Acts: These acts are used to declare something and modify the situations by the uttering of some words (Cutting, 2002).

For example: 'Fall 2014 semester result has been announced.', 'I divorce you!' 


\section{The Social Media}

As new media technologies rise, it is essential to take a view of the shared characteristics and contrasts in attributes and utilizations of these communication devices. One developing innovation rapidly turning into a social staple is the social network site (Boyd \& Ellison, 2008). One of the most famous web administrations is Facebook.com, which has more than 68 million dynamic clients. With millions of clients on these social network sites (SNSs) taking part in both presentation toward oneself and relational communication, SNSs bear the cost of another lens through which to consider human connection (Boyd \& Ellison, 2008). Language is used in these asynchronous media in ways that are similar or different from the ways language is used in the asynchronous applications of a traditionally-synchronous media such as Instant Messaging applications. This study looked to see how language (and hence character) is developed in rising SNSs.

Social Media are sites and applications that empower clients to make and offer substance or to take part in person to person communication. Social networking alludes to the method for communications among individuals in which they make, impart, and/or trade data and thoughts in virtual groups and systems. This digital communication deals with Facebook, Twitter, Instagram, Foursquare, YouTube, Daily Motion, Vimeo accounts and many more. However for this study, we have chosen Facebook and Twitter.

\section{Message - Reflecting Point of View}

Communication and brain study researchers have long comprehended that there is an association in the middle of speech and action. Past experimental exploration has shown that the messages a man conveys can influence that individual's mentality around a subject, actually goes as far as to transform an unfavorable disposition into an ideal one (Freedman \& Fraser, 1966). According to Schwartz et al. (2013), a critical outlook on language on social media can bring accurate deductions about the user's personality, particularly regarding the gender differences.

\section{Effects of Social Media}

The social media affects our face to face conversation. They are not physically present in front of one another; rather they are connected through this media. Even if some people are altogether sitting in the same room they are so busy in using these sites that they cannot communicate with each other. Connection establishes as the relationship moves from a face to face to an online setting. The growing trend of using Social Media for 
staying connected with your close ones led to exploration of speech acts and online messaging, by looking at how people utilize the status messages in informal community destinations (particularly Facebook and Twitter) to impart their perspectives, socially and to develop their personality.

Interestingly, from the feminist perspective, there have been numerous studies highlighting how constructively social media is being used by females for activism (Cullen, 2013). Furthermore, Carstensen (2009) is of the view that this virtual platform has become a useful place to know about gender struggles. Hence, the current study deemed this platform as a suitable area to investigate gender differences.

\section{Popular Social Media Platforms}

The following two social media platforms' data was selected for the study, based on their immense popularity world:

\section{Facebook}

Facebook is considered the world's biggest informal community, with more than 1.32 billion month to month dynamic clients (Solo-Anaeto \& Jacobs, 2015). Clients make an individual profile, and then they include different clients as companions, and trade messages, including announcements. Brands make pages and Facebook clients can "like" brands' pages.

\section{Twitter}

Twitter is like a micro-blogging juncture that permits people to stay associated through the trading of short status messages (Kwak et al., 2010) within the limited space of 140 characters per one update. Every status update is publically viewable to everyone and, hence, this feature makes it a viable platform for people to openly share their views with the world.

\section{Language Use: The Gender Differences}

There is a difference in language used by men and women as established by past researches (Holmes, 1995) within the field of language and gender. According to majority of such studies, language that is used by men is significantly related to aggression, adventure, competition etc. Their language is also less expressive and less emotional. Language that is used by women is sensitive, compassionate, open and illuminating. Women communicate to make relationships, express feelings, on the other 
hand men communicate to have power and they believe on reality mostly. Women's language is polite and men's language is aggressive because they have a greater position than women in the society, generally, owing to their masculinity. Men and women's written discourse is not the same.

According to Lakoff (1975), men and women use language that is mainly related to their interaction with other speech communities. The same issue was highlighted by Bavelas et al. (2000), moreover, they pointed out that the gender differences in written discourse provides a unique perspective to study language. Furthermore, Holmes (1997) highlighted that there is a lot of evidence of inequality in the matter of language among men and women. Hence, for comprehending the unique linguistic qualities of both genders, belonging to Pakistan, the current study aimed to investigate their written status updates on Facebook and Twitter.

\section{Research Methodology}

In this segment, the whole process of research sampling, design and method has been elaborated. The data is qualitatively analyzed according to the selected framework. After that, the analysis is modified into a quantitative structure to get a clear idea.

\section{Population}

A huge group of people or objects that become a research source of data is known as research population. A set of population comprises of all of the components, for instance, objects, events or even individuals (Burns \& Groove, 1993). In this research, the social media users of Facebook and Twitter on the Pakistani social media have been taken as the population for this research.

\section{Sampling}

The sample size determination formulae had been employed to obtain an estimate of the required samples from the population. The minimum number of samples needed for the results to be reliable was 600 . The researchers selected 1000 samples in order to establish the reliability of the study's findings. For the research, 250 statuses of Pakistani Females were selected from Facebook and Twitter each, making it a total of 500. The same numerical figure was kept for the Pakistani Males. It was ensured to select only those statuses which were public for everyone to read - so that their privacy is not disturbed. 
Purposive Sampling implies that the researcher already knows what kinds of samples are needed for the research (Patton, 2001) and only those are picked which match the particular criteria. This technique was employed for separating out the Pakistani individuals updates from the rest of the people's statuses. It enabled the study to stay focused on its aim. The profiles were thoroughly investigated to confirm that the person is a Pakistani national. Once this was assured, then the person's public statuses were selected for the study's purpose. For choosing a status from the huge pool, random selection was employed so that every status gets an equal chance of being selected (Frerichs, 2008). These techniques were employed for ensuring reliability of the samples, so that, generalizable findings can be generated.

\section{Method of Research}

The research incorporated a mixed procedure of qualitative and quantitative methods. This methodology is handy in utilizing the best of both approaches (Creswell et al., 2003) and giving out results, which can be generalizable on the target population. To suit this purpose, firstly, the qualitative approach was utilized in analyzing the utterances in accordance with Searle's Taxonomy. After this, the quantitative approach was utilized in converting qualitatively analyzed data into numerical figures. These numerical findings were then tabulated and then, illustrated in the form of graphs for a clear representation. Lastly, ANOVA was applied to validate a significant similarity or difference in the data.

\section{Analysis of Data}

After a careful examination of speech acts used in the language by the males and females on Pakistani social sites, the researchers examined, classified and sorted under the guidance of the theoretical framework. This analysis included qualitatively analyzing data, then converting the data into quantitative form having frequencies and percentages to give a clear estimate of the result. This inference facilitates in displaying the results properly. Hence, such a combination of both the qualitative and quantitative procedures assists in acquiring a more dynamic reflection of the analysis.

\section{Theoretical Framework}

Theoretical framework binds the data by centering the attention on important variables and describing the important point of view that researcher should take in examining and understanding the data that is collected. Theoretical framework requires the researcher to have sufficient data to generate the theory in the research context (Leedy \& Ormord, 2005). A theoretical structure is a structure of orientation that is a basis for description of ideas, clarifications, explanations, research plans and overviews as the structure that rely on a groundwork defining the general plan of a house (LoBiondo-Wood \& Haber, 1998). The current study utilizes Searle's Taxonomy (1969) which is based on the Speech Act 
Theory. It gives the linguistic markers and description for demarcating and categorizing Speech Acts into the following five categories:

- Assertive Acts: They include the acts of conclusion, prediction, assertion etc.

- Directive Acts: They include the acts of giving order, suggestions, requests.

- Commissive Acts: These comprise of the acts of vowing, offering etc.

- Expressive Acts: These acts include expression of feelings of happiness or sadness.

- Declarative Acts: Such acts which change the world with their declaration and announcement.

Furthermore, the functions of Speech Acts have been elaborated under the guidance of the analysis presented by Wulandari (2014). He displayed the following 30 functions: 1 . Describing, 2. Asserting, 3. Informing, 4. Commanding, 5. Requesting, 6. Persuading, 7. Prohibiting, 8. Asking, 9. Suggesting, 10. Offering, 11. Promising, 12. Sorrow, 13. Pleasure, 14. Congratulating, 15. Greeting, 16. Apology, 17. Boring, 18. Longing, 19. Confusing, 20. Disappointing, 21. Dislike, 22. Hoping, 23. Satisfying, 24. Scaring, 25. Supporting, 26. Thanking, 27. Tiredness, 28. Yearning, 29. Anger, 30. Declaring.

The current study found some new functions as well by analyzing the Pakistani context in particular.

\section{Research Tool}

The written statuses of males and females Pakistani on the social media were examined by the researcher using the structure and its procedures. In this scenario, content analysis of the status updates was the research tool used to scrutinize the language of the status updates. Findings from the samples were then quantified to make valid interpretations.

\section{Triangulation}

The current research employs Investigator Triangulation in order to establish the reliability of the findings of the current study. Within this technique, the same analysis is conducted by different researchers and if their results match, then it indicates that the findings are reliable and thus, valid. This research incorporated analysis of four different investigators for establishing reliability.

\section{Results and Discussion}

The aim of this chapter is to elaborate the findings and interpret them. The resulting analysis would be quantified for depicting the implication and importance of the current study. The findings have been compared with one another through ANOVA and, lastly, an overall analysis has been presented. 


\section{Speech Acts Used by Pakistani Males on Facebook}

After analyzing the status updates of Pakistani Males on Facebook, the following findings have been deduced from the collected data and have been presented in a tabulated form:

Table: 1

Pakistani males' speech acts on facebook

\begin{tabular}{|l|c|c|}
\hline Types of speech acts & Amount & Percentage \\
\hline Assertive & 64 & $24.90 \%$ \\
\hline Directive & 65 & $25.29 \%$ \\
\hline Declarative & 55 & $21.40 \%$ \\
\hline Expressive & 70 & $27.23 \%$ \\
\hline Commissive & 3 & $1.16 \%$ \\
\hline Total & $\mathbf{2 5 7}$ & \\
\hline
\end{tabular}

The total number of speech acts found in the respective 250 Male's Facebook statuses was 257 . Hence, this figure implies that one status update could include more than one speech act in it. The results indicate that the most extensively used speech act is Expressive act $(27.23 \%)$ by the Pakistani Males on Facebook. The second mostly used Speech act is the Directive speech act with a percentage of $25.29 \%$. Lastly, the Commissive act is least employed by the Pakistani Males on Facebook, according to the findings of this study.

An illustrative graphic representation of the findings is as follows:

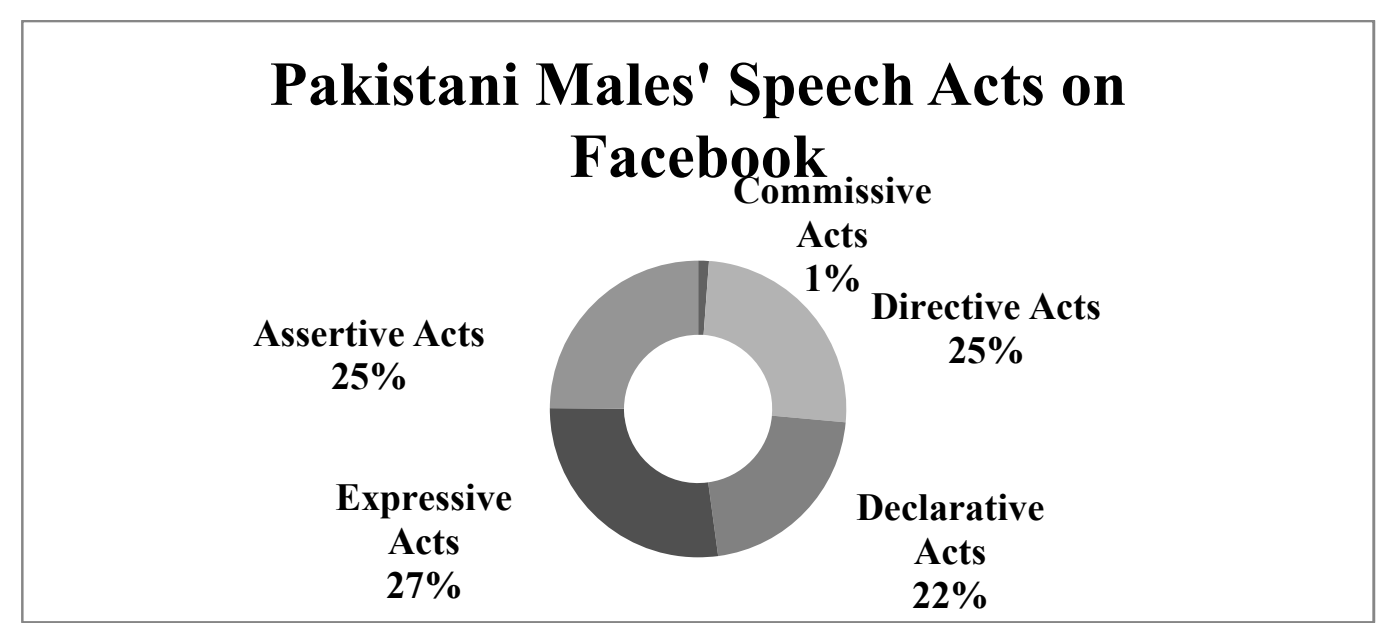

Figure 1: Pakistani Males' Speech Acts on Facebook 


\section{Communicative Functions of the Speech Acts Used by Pakistani Males on Facebook}

Furthermore, the functions of the speech acts used by the Pakistani males on the platform of Facebook have also been extensively studied. The results have been tabulated for clarity, as below:

Table: 2

Communicative functions of pakistani males' speech acts on facebook

\begin{tabular}{|c|c|c|}
\hline The Functions of Speech Acts & Amount & Percentage \\
\hline Disappointing & 4 & $0.95 \%$ \\
\hline Anger & 4 & $0.95 \%$ \\
\hline Thanking & 5 & $1.19 \%$ \\
\hline Informing & 177 & $42.14 \%$ \\
\hline Prohibiting & 11 & $2.61 \%$ \\
\hline Hating & 1 & $0.23 \%$ \\
\hline Asserting & 51 & $12.14 \%$ \\
\hline Wishing & 1 & $0.23 \%$ \\
\hline Requesting & 6 & $1.42 \%$ \\
\hline Suggesting & 17 & $4.04 \%$ \\
\hline Asking & 20 & $4.76 \%$ \\
\hline Congratulating & 2 & $0.48 \%$ \\
\hline Describing & 2 & $0.48 \%$ \\
\hline Declaring & 38 & $9.04 \%$ \\
\hline Commanding & 9 & $2.14 \%$ \\
\hline Hoping & 1 & $0.23 \%$ \\
\hline Sorrow & 4 & $0.95 \%$ \\
\hline Supporting & 2 & $0.48 \%$ \\
\hline Greeting & 3 & $0.71 \%$ \\
\hline Confusing & 2 & $0.48 \%$ \\
\hline Committing & 2 & $0.48 \%$ \\
\hline Expressing & 26 & $6.19 \%$ \\
\hline Pleasure & 17 & $4.04 \%$ \\
\hline Dislike & 1 & $0.23 \%$ \\
\hline Yearning & 2 & $0.48 \%$ \\
\hline Warning & 1 & $0.23 \%$ \\
\hline Ordering & 3 & $0.71 \%$ \\
\hline Advising & 3 & $0.71 \%$ \\
\hline Longing & 4 & $0.95 \%$ \\
\hline Exciting & 1 & $0.23 \%$ \\
\hline Total & 420 & \\
\hline
\end{tabular}


Out of the 250 Status Updates of Males on Facebook, 420 communicative functions were found. This implies that Pakistani Males tend to achieve a variety of communicative goals, while uploading their status - instead of achieving just one communicative function at a time.

The results from the above table display the fact that a total of 30 communicative functions were performed by the particular speech acts jotted down by the Pakistani Males on Facebook. If we study these findings more elaborately, we can see that there are 3 functions of Assertive act which include: describing (0.48\%), asserting (12.14\%) and informing (42.14\%). Furthermore, there are 8 functions of Directive act as well, which include: prohibiting (2.61\%), requesting (1.42\%), suggesting (4.04\%), asking $(4.76 \%)$, commanding $(2.14 \%)$, warning $(0.23 \%)$, ordering $(0.71 \%)$, advising $(0.71 \%)$. Moreover, the Commissive act has only 1 function which is committing $(0.48 \%)$. Additionally, the declarative act has also only 1 function too, which is declaring $(9.04 \%)$.

Lastly, the Expressive act has 18 functions, which comprises of the following: disappointing $(0.95 \%)$, anger $(0.95 \%)$, thanking $(1.19 \%)$, hating $(0.23 \%)$, wishing $(0.23 \%)$, congratulating $(0.48 \%)$, hoping $(0.23 \%)$, sorrow $(0.95 \%)$, supporting $(0.48 \%)$, greeting $(0.71 \%)$, confusing $(0.48 \%)$, expressing $(6.19 \%)$, pleasure $(4.04 \%)$, dislike $(0.23 \%)$, yearning $(0.48 \%)$, longing $(0.95 \%)$, exciting $(0.23 \%)$. Hence the total functions of speech acts that appear in Facebook statuses of males are 30 within the selected 250 updates of Pakistani Males' status messages. The tabulated data has been graphically represented as follows:

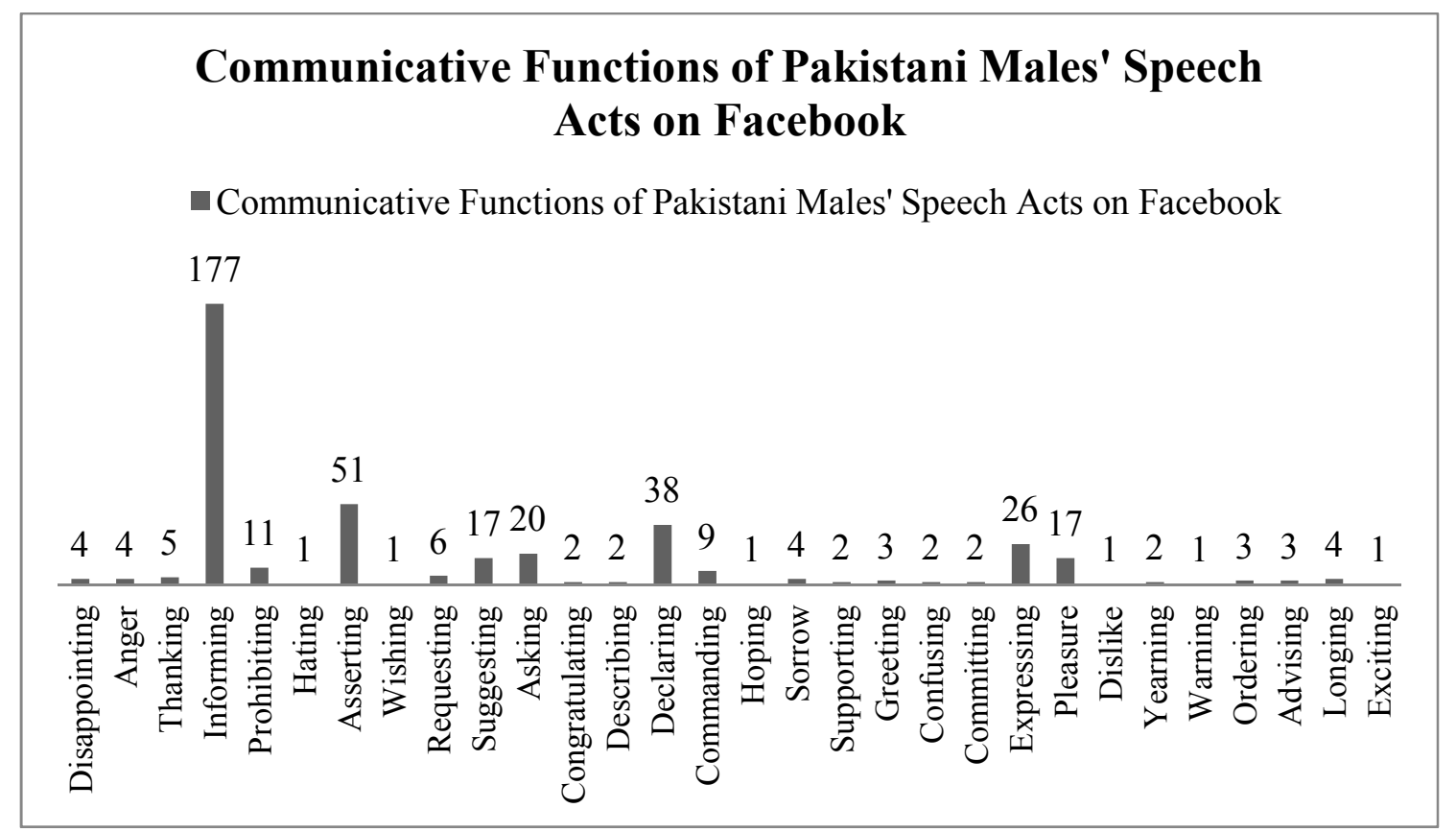

Figure 2: Communicative Functions of Pakistani Males' Speech Acts on Facebook 


\section{Speech Acts Used by Pakistani Females on Facebook}

Based on the findings, Pakistani Females language use while penning down status updates, is majorly pertaining to the use of Directive Acts. This result elaborates that the social tool of Facebook is utilized by them to give suggestions, requests, and pieces of advice or commands through their status updates. The following table explains the frequency and percentages for each category of speech acts, as utilized by the Pakistani Females in their language use:

Table: 3

Speech acts used by pakistani females on facebook

\begin{tabular}{|l|c|c|}
\hline Types of Speech Acts & Amount & Percentage \\
\hline Assertive & 55 & $22 \%$ \\
\hline Directive & 114 & $45.6 \%$ \\
\hline Declarative & 13 & $5.2 \%$ \\
\hline Expressive & 68 & $27.2 \%$ \\
\hline Commissive & 0 & $0 \%$ \\
\hline Total & $\mathbf{2 5 0}$ & \\
\hline
\end{tabular}

A total of 250 speech acts were found in the 250 status updates of Pakistani females on Facebook. This number is quite near to the quantity of speech acts found among Pakistani males (i.e. 257 speech acts) on Facebook. However, a closer view on the speech acts' application brings out clear differences.

The above given Table 3 depicts that Directive acts were most extensively used by the Pakistani Females on Facebook as their percentage use amounts to 45.6\%. The next most frequently used speech acts were the Expressive acts as their percentage comes out to be $27.2 \%$. Furthermore, the third most used speech act was the Assertive Act as its percentage appeared as $22 \%$. Lastly, the Declarative act was used quite rarely as its use reaches to $5.2 \%$ percent. Another notable fact is that the Commissive Act was not found in use within this category, which is why, the percentage of it dropped to zero percent.

The illustrative chart for clarifying the findings within this category is as follows:

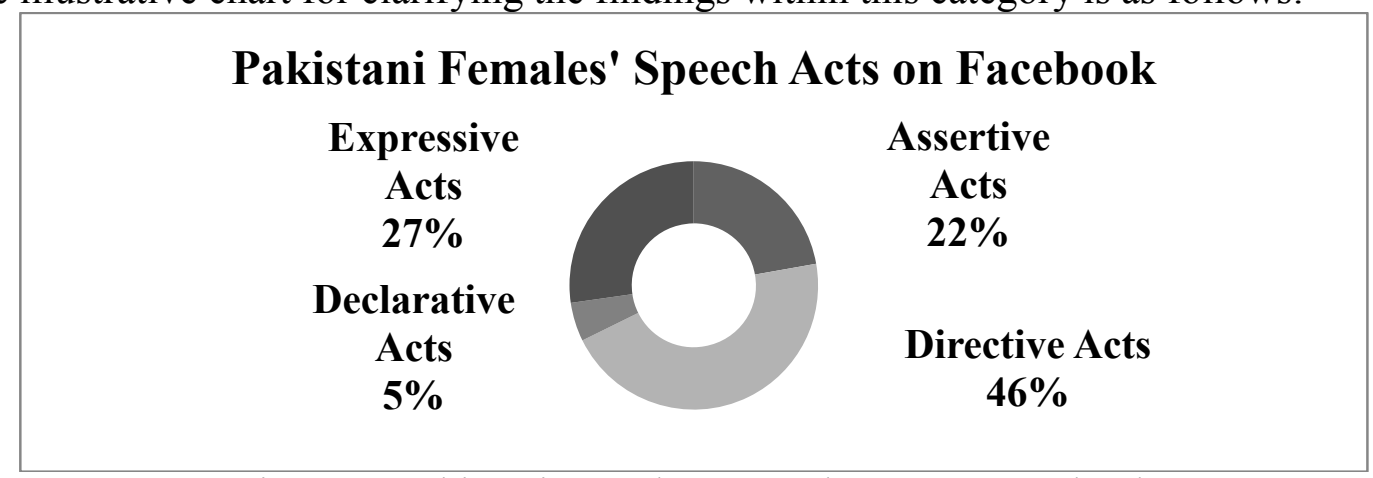

Figure 3: Pakistani Females' Speech Acts on Facebook 


\section{Communicative Functions of the Speech Acts Used by Pakistani Females on Facebook}

Analyzing the communicative function of a particular utterance not only helps in deciphering the meaning of the statement, but also aids in exploring the vast variety of means which language serves for the speakers to convey their message towards a particular set of audience explicitly or implicitly. A total of 23 communicative functions were found within the selected Facebook utterances of the Pakistani females. The following table gives a clear understanding of the various communicative functions performed by every status update of the Pakistani Females on the platform of Facebook, along with their respective calculated percentages for each particular function:

Table: 4

Communicative functions of pakistani females' speech acts on facebook

\begin{tabular}{|l|c|c|}
\hline The Function of Speech Acts & Amount & Percentage \\
\hline Disappointing & 2 & $1.07 \%$ \\
\hline Anger & 12 & $6.45 \%$ \\
\hline Thanking & 2 & $1.07 \%$ \\
\hline Informing & 21 & $11.29 \%$ \\
\hline Prohibiting & 19 & $10.21 \%$ \\
\hline Asserting & 34 & $18.27 \%$ \\
\hline Wishing & 4 & $2.15 \%$ \\
\hline Requesting & 4 & $2.15 \%$ \\
\hline Suggesting & 30 & $16.12 \%$ \\
\hline Describing & 1 & $0.53 \%$ \\
\hline Declaring & 8 & $4.30 \%$ \\
\hline Commanding & 1 & $0.53 \%$ \\
\hline Sorrow & 4 & $2.15 \%$ \\
\hline Greeting & 2 & $1.07 \%$ \\
\hline Expressing & 17 & $9.13 \%$ \\
\hline Pleasure & 11 & $5.91 \%$ \\
\hline Longing & 3 & $1.61 \%$ \\
\hline Loving & 5 & $2.68 \%$ \\
\hline Begging & 1 & $0.53 \%$ \\
\hline Boring & 2 & $1.07 \%$ \\
\hline Inviting & 1 & $0.53 \%$ \\
\hline Ending & 1 & $0.53 \%$ \\
\hline Celebrating & 1 & $0.53 \%$ \\
\hline Total & $\mathbf{1 8 6}$ & \\
\hline
\end{tabular}

Interestingly, the total communicative functions found in 250 status updates of Pakistani females are 186. It indicates that there is more variety of communicative functions employed by males of Facebook as compared to females (males' communicative functions were 420 in total, within the 250 status updates limit). This numerical output also highlights that some statuses of females (approximately 64 status updates) were 
uploaded not for the sake of fulfilling a communicative goal with perspective from the audience. Rather, these statuses were neutral (in terms of achieving a communicative goal) and were not uploaded for gathering reactions or responses from the audience.

From the above table, it can be deciphered that there are 3 functions of Assertive act as describing $(0.26 \%)$, asserting $(9.06 \%)$ and informing $(56 \%)$. Furthermore, there are 5 functions of directive as well, which includes prohibiting $(5.06 \%)$, requesting $(1.06 \%)$, inviting $(0.26 \%)$ suggesting $(8 \%)$ and commanding $(0.26 \%)$. Moreover, the declarative act has only 2 functions within it, which comprise of declaring $(2.13 \%)$ and begging $(0.26 \%)$. Additionally, the expressive act was found to have 12 communicative functions, as shown here, which include disappointing $(0.53 \%)$, boring $(0.53 \%)$, loving $(1.33 \%)$ celebrating $(0.26 \%)$, anger $(3.2 \%)$, thanking $(0.53 \%)$, wishing $(1.06 \%)$, sorrow $(1.06 \%)$, greeting $(0.53 \%)$, expressing $(4.53 \%)$, pleasure $(2.93 \%)$ and longing $(0.8 \%)$, Hence the total functions of speech acts that appear in the Facebook status messages of females are 23 contained in the selected 250 updates. In addition, we can also see that the most frequently occurring communicative function was asserting. Furthermore, a graphical representation, as presented below, helps to give a bird's eye view of the various communicative functions:

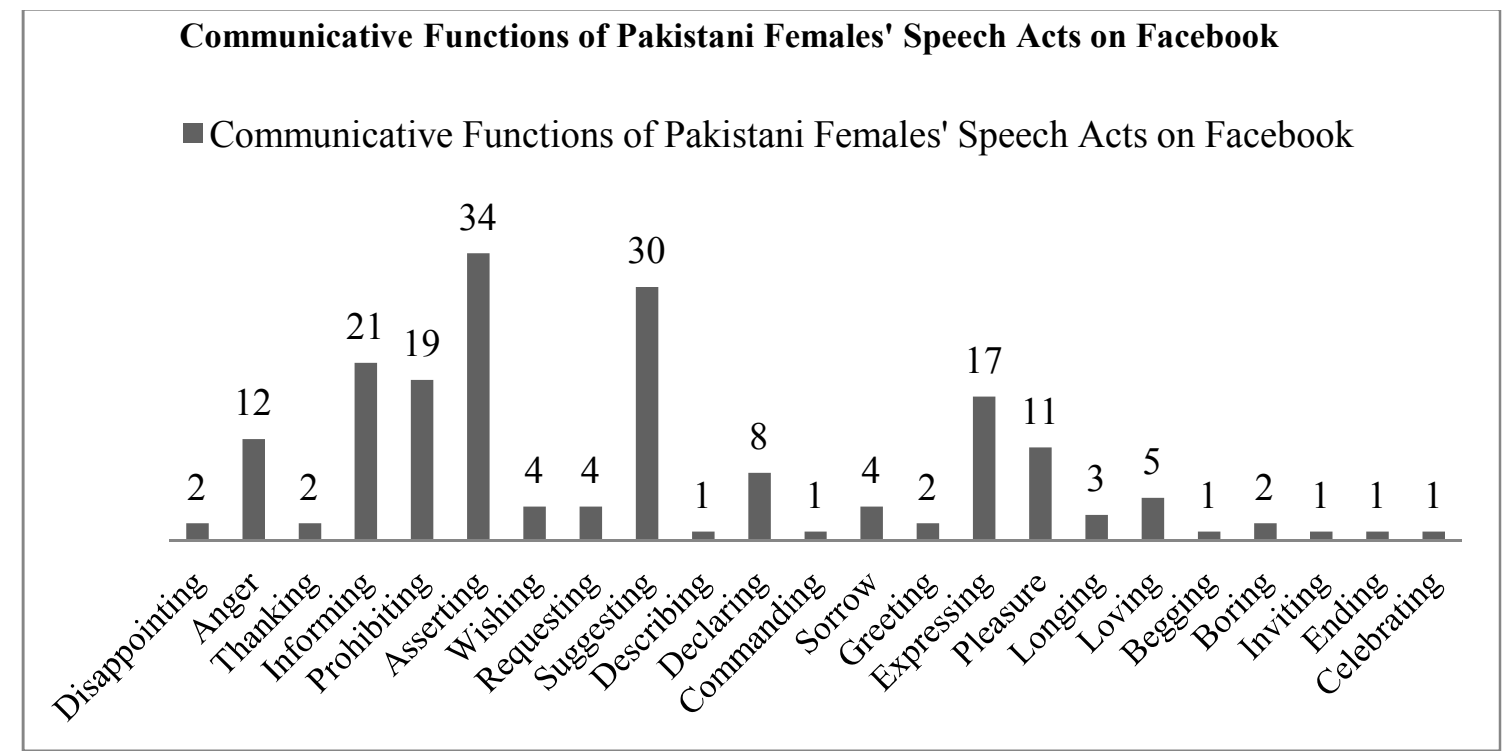

Figure 4: Communicative Functions of Pakistani Females' Speech Acts on Facebook

\section{Speech Acts Used by Pakistani Males on Twitter}

Based on the findings of the current study, the Pakistani males have been observed to make use of Expressive Acts more extensively on the social platform of Twitter. Followed by this particular act, the next most extensively utilized act is the Assertive act. The following table gives a clear idea about the findings: 
Table: 5

Pakistani males' speech acts on twitter

\begin{tabular}{|l|c|c|}
\hline Types of Speech Act & Amount & Percentage (\%) \\
\hline Assertive Act & 69 & $26.64 \%$ \\
\hline Declarative Act & 52 & $20.08 \%$ \\
\hline Directive Act & 24 & $9.27 \%$ \\
\hline Expressive Act & 100 & $38.61 \%$ \\
\hline Commissive Act & 14 & $5.41 \%$ \\
\hline Total & $\mathbf{2 5 9}$ & \\
\hline
\end{tabular}

A total of 259 speech acts were found in 250 status updates of Pakistani males on Twitter. This finding indicates that status in above given table depicts that Expressive acts were most extensively used by the Pakistani males on Twitter as their percentage reaches up to $38.61 \%$. Another notable fact is that the Commissive Act was the least used act within this category, which is why, the percentage of it dropped to $5.4 \%$.

These findings are further elaborated in the following pie chart:

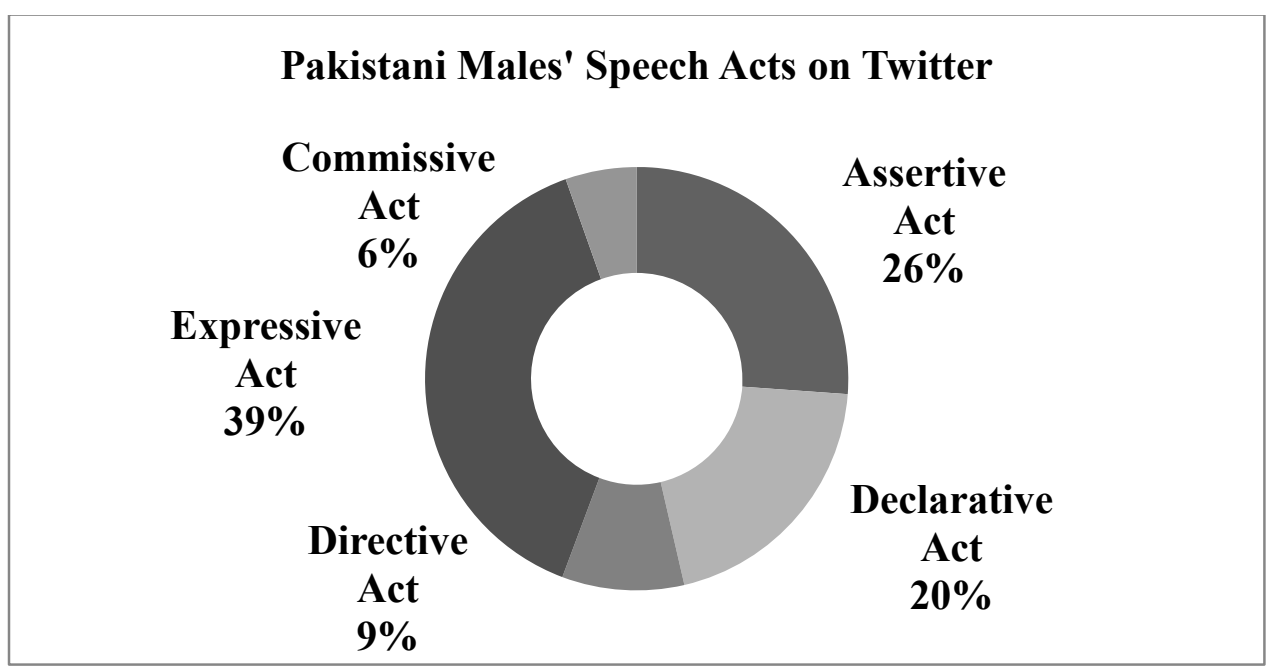

Figure 5: Pakistani Males' Speech Acts on Twitter

\section{Communicative Functions of the Speech Acts Used by Pakistani Males on Twitter}

A total of 35 communicative functions were found within the selected Twitter utterances of the Pakistani males. The following table gives a clear understanding of the various communicative functions performed by every status update of the Pakistani Males on the platform of Twitter, along with their respective calculated percentages for each particular function: 
Table: 6

Communicative functions of pakistani males' speech acts on twitter

\begin{tabular}{|c|c|c|}
\hline The Functions of Speech Act & Amount & Percentage \\
\hline Appeal & 1 & $0.35 \%$ \\
\hline Asking & 19 & $6.69 \%$ \\
\hline Asserting & 1 & $0.35 \%$ \\
\hline Advice & 1 & $0.35 \%$ \\
\hline Anger & 28 & $9.86 \%$ \\
\hline Boring & 2 & $0.70 \%$ \\
\hline Confusing & 1 & $0.35 \%$ \\
\hline Disappointment & 27 & $9.51 \%$ \\
\hline Describing & 4 & $1.41 \%$ \\
\hline Dislike & 6 & $2.11 \%$ \\
\hline Declaring & 3 & $1.06 \%$ \\
\hline Informing & 64 & $22.54 \%$ \\
\hline Persuading & 11 & $3.87 \%$ \\
\hline Hoping & 17 & $5.99 \%$ \\
\hline Stating & 1 & $0.35 \%$ \\
\hline Opinion & 9 & $3.17 \%$ \\
\hline Loving & 1 & $0.35 \%$ \\
\hline Joy & 7 & $2.46 \%$ \\
\hline Thanking & 3 & $1.06 \%$ \\
\hline Pride & 4 & $1.41 \%$ \\
\hline Prays & 1 & $0.35 \%$ \\
\hline Longing & 2 & $0.70 \%$ \\
\hline Pleasure & 5 & $1.76 \%$ \\
\hline Encouraging & 1 & $0.35 \%$ \\
\hline Sorrow & 6 & $2.11 \%$ \\
\hline Request & 3 & $1.06 \%$ \\
\hline Praise & 3 & $1.06 \%$ \\
\hline Supporting & 9 & $3.17 \%$ \\
\hline Greetings & 8 & $2.82 \%$ \\
\hline Satire & 21 & $7.39 \%$ \\
\hline Helping & 1 & $0.35 \%$ \\
\hline Tiredness & 4 & $1.41 \%$ \\
\hline Suggesting & 3 & $1.06 \%$ \\
\hline Wishing & 5 & $1.76 \%$ \\
\hline Warning & 2 & $0.70 \%$ \\
\hline Total & 284 & \\
\hline
\end{tabular}


The communicative functions achieved by 250 males' statuses on Twitter totaled to 284 . This numerical value indicates that certain statuses performed more than one communicative function.

From the above table, it can be easily seen that there are 4 major communicative functions performed by the speech acts of Pakistani Males on Twitter, which comprise of: informing (22.54\%), disappointment (9.51\%), satire (7.39\%), and asking (6.69\%).

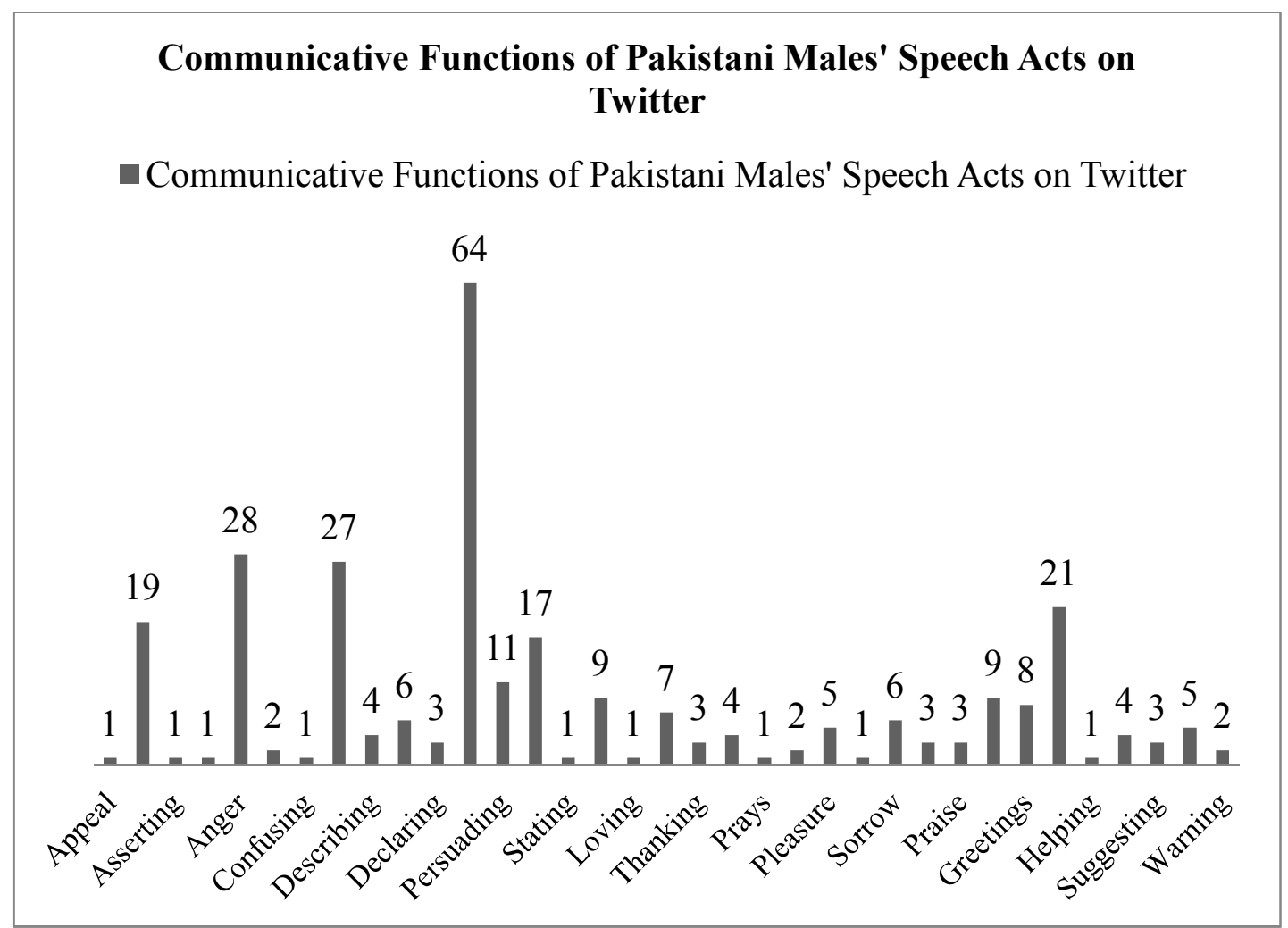

Figure 6: Communicative Functions of Pakistani Males' Speech Acts on Twitter

\section{Speech Acts Used by Pakistani Females on Twitter}

The findings under this set of data reveal that the most extensively used Speech act by the Pakistani Female Twitter users was the Assertive act (41.0\%). After this, they most frequently utilized the Expressive act (34.7\%). The results have been tabulated as follows: 
Table: 7

Pakistani females' speech acts on twitter

\begin{tabular}{|l|c|c|}
\hline Types of speech acts & Amount & Percentage \\
\hline Assertive & 110 & $41.0 \%$ \\
\hline Directive & 56 & $20.8 \%$ \\
\hline Declarative & 6 & $2.23 \%$ \\
\hline Expressive & 93 & $34.7 \%$ \\
\hline Commissive & 3 & $1.11 \%$ \\
\hline Total & $\mathbf{2 6 8}$ & \\
\hline
\end{tabular}

The Pakistani females' status updates contained a total of 268 speech acts enclosed within them. This value indicates that certain status updates enclosed more than one speech act within them. The above tabulated data has been graphically illustrated as following:

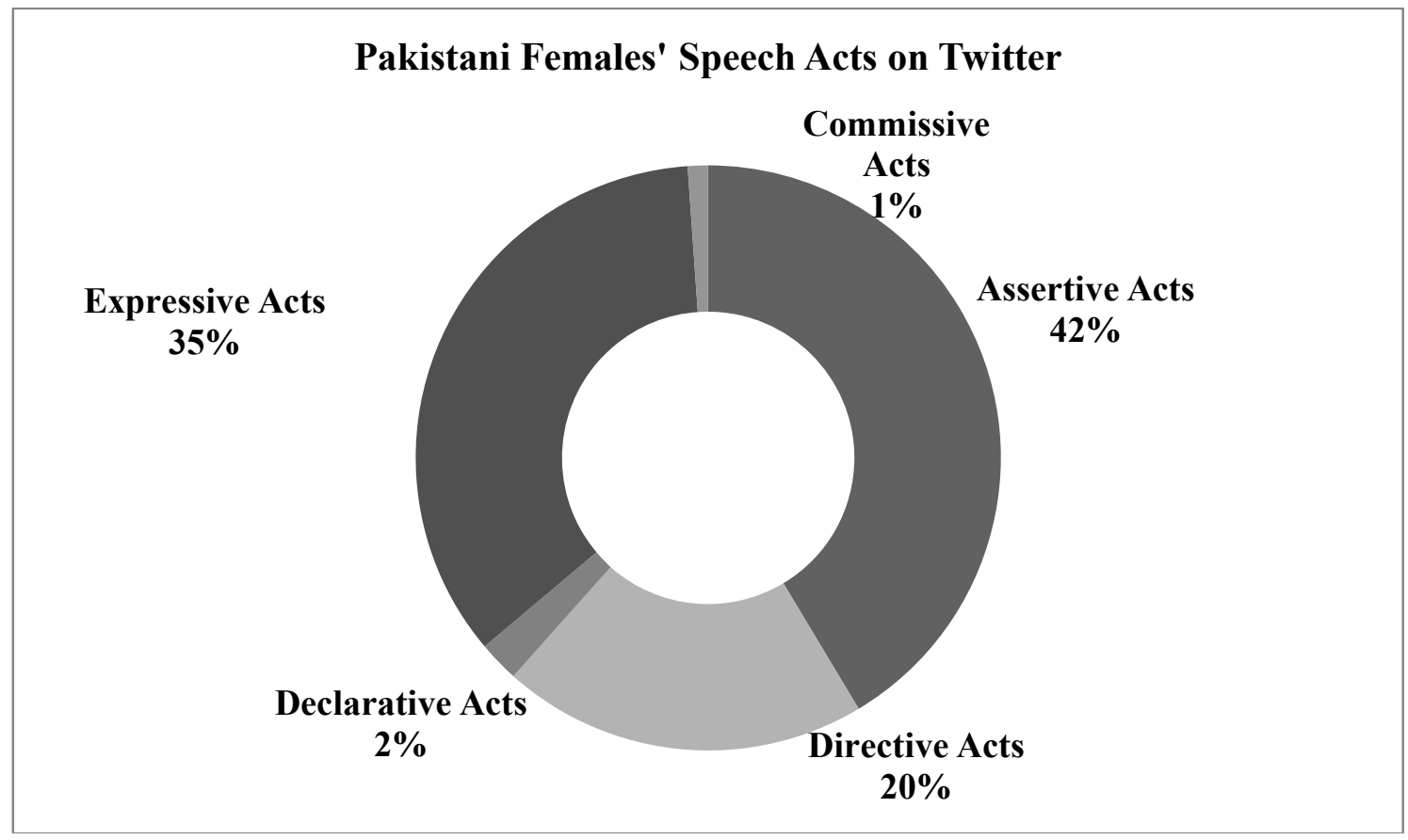

Figure 7: Pakistani Females' Speech Acts on Twitter

\section{Communicative Functions of the Speech Acts Used by Pakistani Females on Twitter}

The intended implication of the particular speech is clarified once we analyze the communicative function of a speech act. The following table presents the various thematic communicative functions of all the speech acts employed by the Pakistani Females on the social platform of Twitter: 
Table: 8

Communicative functions of pakistani females' speech acts on twitter

\begin{tabular}{|l|c|c|}
\hline The Function of Speech Acts & Amount & Percentage \\
\hline Disappointing & 52 & $16.3 \%$ \\
\hline Anger & 17 & $5.34 \%$ \\
\hline Thanking & 9 & $2.83 \%$ \\
\hline Informing & 85 & $26.7 \%$ \\
\hline Prohibiting & 2 & $0.62 \%$ \\
\hline Asserting & 4 & $1.25 \%$ \\
\hline Requesting & 7 & $2.20 \%$ \\
\hline Suggesting & 28 & $8.80 \%$ \\
\hline Asking & 18 & $5.66 \%$ \\
\hline Congratulating & 4 & $1.25 \%$ \\
\hline Describing & 13 & $4.08 \%$ \\
\hline Declaring & 1 & $0.31 \%$ \\
\hline Commanding & 1 & $0.31 \%$ \\
\hline Hoping & 8 & $2.51 \%$ \\
\hline Sorrow & 12 & $3.77 \%$ \\
\hline Supporting & 9 & $2.83 \%$ \\
\hline Greeting & 1 & $0.31 \%$ \\
\hline Confusing & 2 & $0.62 \%$ \\
\hline Pleasure & 6 & $1.88 \%$ \\
\hline Dislike & 22 & $6.91 \%$ \\
\hline Yearning & 1 & $0.31 \%$ \\
\hline Longing & 2 & $0.62 \%$ \\
\hline Offering & 8 & $2.51 \%$ \\
\hline Boring & 1 & $0.31 \%$ \\
\hline Scaring & 4 & $1.25 \%$ \\
\hline Declare & & $0.31 \%$ \\
\hline Total & 18 & \\
\hline & & \\
\hline & 12 & \\
\hline
\end{tabular}

The total communicative functions performed by Pakistani Females' Speech Acts on Twitter are 318. This total is higher than the communicative functions produced by Females' status updates on Facebook (i.e. 186). This indicates towards another finding that females tend to be more communicative on Twitter rather than on Facebook. Furthermore, the communicative functions performed by Females on Twitter are more than Males on Twitter. This finding strengthens the previous conclusion of Pakistani females achieving more communicative goals on Twitter than on Facebook. 
From the above table, it is depicted that there are 4 functions of Assertive act, which include: describing (4.08\%), asserting (1.25\%), informing $(26.7 \%)$ and boring $(0.31 \%)$. Moreover, there are 6 functions of Directive act which comprise of: prohibiting $(0.62 \%)$, requesting $(2.20 \%)$, suggesting $(8.80 \%)$, asking $(5.66 \%)$, offering $(2.51 \%)$ and commanding $(0.31 \%)$. The Declarative act has also only 1 communicative function, which includes: declaring (0.31\%). Lastly, the Expressive act has 15 functions which include: disappointing $(16.3 \%)$, anger $(5.34 \%)$, thanking $(2.83 \%)$, congratulating $(1.25 \%)$, hoping $(2.51 \%)$, sorrow $(3.77 \%)$, supporting $(2.83 \%)$, greeting $(0.31)$, confusing $(0.62 \%)$, expressing $(0 \%)$, pleasure $(1.88 \%)$, dislike $(6.91 \%)$, yearning $(0.31 \%)$, longing $(0.61 \%)$ and scaring(1.24\%). Thus, the total communicative functions of speech acts that appear in the status updates of Twitter's Pakistani Female Users are 26. The tabulated data has been illustratively presented as follows:

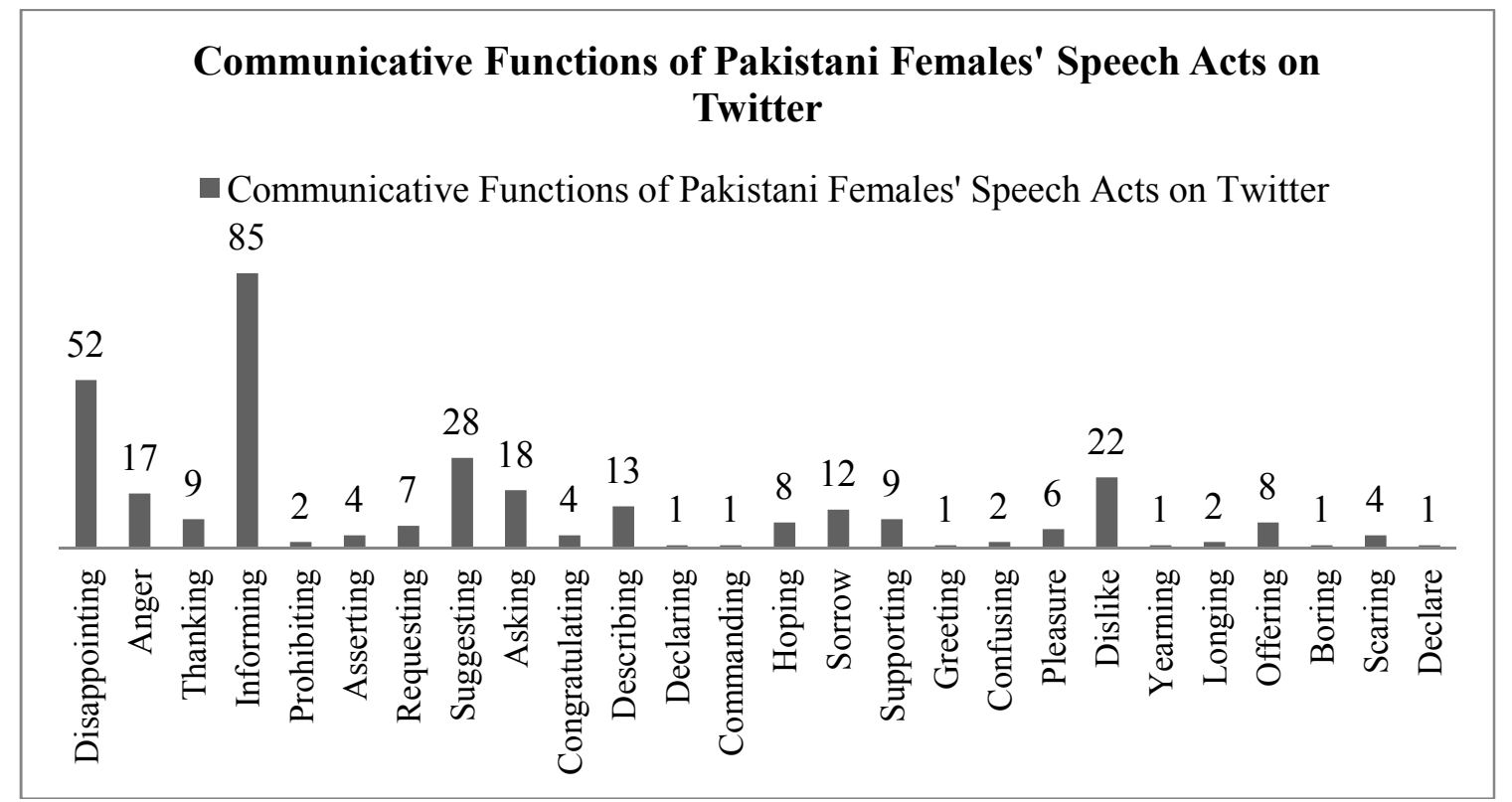

Figure 8: Communicative Functions of Pakistani Females' Speech Acts on Twitter

\section{Comparison of Pakistani Males' and Females' Speech Acts: The Overall Findings}

The findings reveal that Pakistani Males tend to use the Expressive Act most extensively on both of the Social Media Platforms (Facebook and Twitter). However, this is not the case with the Females use of Speech Acts; the Pakistani females tend to use the Directive Acts and Assertive Acts mostly on the Social Media Platforms (Facebook and Twitter). This evidence itself validates that there is a difference in the use, intention and meaning of the language used by a man and woman. 
Using SPSS Software, ANOVA test was applied on the complete data set in order to compute verified differences and similarities in the use of Speech Acts by the Males and Females on Facebook and Twitter. The results are in the following table:

ANOVA

\begin{tabular}{|c|c|c|c|c|c|c|}
\hline & & $\begin{array}{c}\text { Sum of } \\
\text { Squares }\end{array}$ & df & $\begin{array}{c}\text { Mean } \\
\text { Square }\end{array}$ & $\mathbf{F}$ & Sig. \\
\hline \multirow[t]{3}{*}{ Assertive } & $\begin{array}{l}\text { Between } \\
\text { Groups }\end{array}$ & .955 & 1 & .955 & 4.667 & .031 \\
\hline & Within Groups & 211.161 & 1032 & .205 & & \\
\hline & Total & 212.116 & 1033 & & & \\
\hline \multirow[t]{3}{*}{ Directive } & $\begin{array}{l}\text { Between } \\
\text { Groups }\end{array}$ & 2.660 & 1 & 2.660 & 13.412 & .000 \\
\hline & Within Groups & 204.679 & 1032 & .198 & & \\
\hline & Total & 207.339 & 1033 & & & \\
\hline \multirow[t]{3}{*}{ Declarative } & $\begin{array}{l}\text { Between } \\
\text { Groups }\end{array}$ & 3.504 & 1 & 3.504 & 42.435 & .000 \\
\hline & Within Groups & 85.208 & 1032 & .083 & & \\
\hline & Total & 88.712 & 1033 & & & \\
\hline \multirow[t]{3}{*}{ Expressive } & $\begin{array}{l}\text { Between } \\
\text { Groups }\end{array}$ & .090 & 1 & .090 & .412 & .521 \\
\hline & Within Groups & 224.952 & 1032 & .218 & & \\
\hline & Total & 225.042 & 1033 & & & \\
\hline \multirow[t]{3}{*}{ Commissive } & $\begin{array}{l}\text { Between } \\
\text { Groups }\end{array}$ & .191 & 1 & .191 & 10.128 & .002 \\
\hline & Within Groups & 19.423 & 1032 & .019 & & \\
\hline & Total & 19.613 & 1033 & & & \\
\hline
\end{tabular}

In the last column of this table, the significant values have been determined. We can see that the values for Assertive, Directive, Declarative and Commissive acts are less than 0.05 which implies that the differences of these values among the groups of males and females are significant. Whereas, the significant value for Expressive acts is 0.521 (which is less than 0.05) and this implies that the use of trend of using Expressive acts is similar in both males and females. Thus, overall, we can conclude that there is a significant difference in the use of language between Pakistani males and Pakistani females on the social media platforms.

It also shows that the Males, being aggressive in their language use, prefer to vent out their emotions on such an online platform, where they know that they will be listened to. On the other hand, Females being calm and sophisticated in their language use, tend to employ Directive acts where they might like to suggest, request or sometimes even order 
something; and, also they prefer to utilize the explanatory strategy of Assertive acts where they tend to discuss, negotiate and explain a particular notion, instead of simply expressing it.

Furthermore, there is a noticeable gender-based difference in the communicative functions as well. Pakistani Males tend to use their status for the purpose of informing most widely. However, Pakistani Females not only exercise their status for the communicative function of informing, but they also utilize it for asserting and suggesting as well.

Thus, the analysis displays that the Social Media is not just a platform for general communication or chit-chat; rather it is a space where a person is heard as well. From every statement, there is an implicit meaning deduced by the hearer, this makes it a useful platform to study the society in general. Self-expression in the current digital world is done through such online forums easily (Ilyas \& Khushi, 2012). In such a way, people reveal their gender-based identities as well, which have been deciphered by the current study. The use of language shapes up the perspectives and mind set of the person and that is how these platforms are, as Hills (2009, p.115) remarks, 'powerfully linked to forms of self-identity, self- expression and self-display.'

\section{Conclusions}

The study aimed to investigate and highlight the differences and similarities of language use, particularly with the use of Speech Acts, on the popular online social platforms of Facebook and Twitter. Results revealed insights into gender-based differences in language use. Pakistani Males tend to use the Expressive Acts more often within their language while updating their status messages on Facebook and Twitter; on the other hand, the Pakistani Females prefer to employ the Directive and Assertive Acts more frequently in their language on the Facebook and Twitter status updates.

Furthermore, the Pakistani Males utilize the status messages as a source of informing their potential audience about something. While, the Pakistani Females make use of the status messages to achieve multiple purposes, which majorly include: informing, suggesting and asserting, according to the findings of the current study.

Thus, the study's results bring awareness that there is a linguistic difference in the language use of the Males and Females of Pakistan as well. It helps to validate that gender-based differences are part of the identity of a person and these are reflected through the medium of language, and thus, such a linguistic study can elaborately reveal these differences. 


\section{References}

Austin, J. L. (1962). How to Do Things with Words. Clarendon: Oxford University Press.

Bavelas, J. B., Coates, L. \& Johnson, T. (2000). Listeners as Co-Narrators. Journal of Personality and Social Psychology, vol.79, pp.941-952.

Boyd, D. \& Ellison, N. B. (2008). Social Network Sites: Definition, History, and Scholarship. Journal of Computer-Mediated Communication, vol.13:1, pp.210-230. Retrieved from: http:/ /jcmc.indiana.edu/vol13/issue1/boyd.ellison.html

Burns, N. \& Grove, S. K. (1993). The Practice of Nursing Research. Conduct, Critique and Utilization. Philadelphia: Saunders.

Carstensen, T. (2009). Gender Trouble in Web 2.0. Gender Perspectives on Social Network Sites, Wikis and Weblogs. Retrieved from http://www.informatik.unibremen.de/soteg/gict2009/proceedings/GICT2009_Carstensen.pdf

Creswell, J. W. (2003). Research Design: Qualitative, Quantitative, and Mixed Method Approaches. Thousand Oaks, Calif: Sage Publications.

Crystal, D. (2000). Language Death. Cambridge, UK: CUP.

Cullen, E. (2013). A Study of Feminist Activity for Social Change in the Global Twitter Sphere. Retrieved from: http://www.diva-portal.org/smash/get/diva2:647457/ FULLTEXT01.pdf

Cutting, J. (2002). Pragmatics and Discourse. USA, Canada: Routledge.

Das, B.K. (2005). Twentieth Century Literary Criticism. New Delhi: Atlantic Publishers.

Freedman, J. L. \& Fraser, S. C. (1966). Compliance Without Pressure: The Foot-in-theDoor Technique. Journal of Personality and Social Psychology, vol.4:2, pp.195. New York: Sage Publishers.

Frerichs, R. R. (2008). Simple Random Sampling. Retrieved on May 10, 2015 from: http://www.ph.ucla.edu/epi/rapidsurveys/RScourse/RSbook_ch3.pdf

Hills, M. (2009). Participatory Culture: Mobility, Interactivity and Identity. In G. Creeber, \& R. Martin (Eds.), Digital Cultures: Understanding New Media, pp. 30-38, New York: McGraw Hill Open University Press. 
Holmes, J. (1995). Women, Men and Politeness. London: Longman

Holtgraves, T.M. (2002). Language as Social Action: Social Psychology and Language Use. New Jersey, London: Lawrence Erlbaum Associates.

Ilyas, S. \& Khushi, Q. (2012). Facebook Status Updates: A Speech Act Analysis. Academic Research International, vol.3:2, pp.500-507.

Kreidler, C. W. (1998). Introducing English Semantics. New York, NY: Routledge.

Kwak, H., Lee, C., Park, H. \& Moon, S. (2010). What is Twitter, a Social Network or a News Media? Retrieved from: http:/www.ambuehler.ethz.ch/CDstore/www2010/ www/p591.pdf

Lakoff, R. (1975). Language and Woman's Place. New York: Harper \& Row.

Leedy, P. D. \& Ormrod, J. E. (2005). Practical Research: Planning and Design. Upper Saddle River, NJ: Prentice Hall.

LoBiondo-Wood, G., \& Haber, J. (1998). Nursing Research: Methods, Critical Appraisal and Utilization. St. Louis, MO: Mosby.

Newman, M. L., Groom, C. J., Handelman, L. D. \& Pennebaker, J. W. (2008). Gender Differences in Language Use: An Analysis of 14,000 Text Samples. Discourse Processes, vol.45, pp.211-236.

Patton, M. (2001). Qualitative Research and Evaluation Method. Thousand Oaks, CA: Sage Publishers.

Sadock, J. (2009). Speech Acts. In L. R. Horn, \& G. Ward (Eds.), Handbook of Pragmatics. USA, UK, Australia: Blackwell Publishing.

Schwartz HA, Eichstaedt JC, Kern ML, Dziurzynski L, Ramones SM, et al. (2013). Personality, Gender, and Age in the Language of Social Media: The Open-Vocabulary Approach. PLOS ONE, vol.8:9, p.e73791.https://doi.org/ 10.1371/journal.pone.0073791

Searle, J.R. (1969). Speech Acts. Cambridge: Cambridge University Press. 
Singh, M. P. (1991). Social and Psychological Commitments in Multiagent Systems. Retrieved from: https://www.csc2.ncsu.edu/faculty/mpsingh/papers/mas/fallsymp-91-longer.pdf

Social Bakers. (2012a). Facebook Statistics by Country. Retrieved on April 26, 2015 from: http://www.socialbakers.com/facebook-statistics

Social Bakers. (2012b). Twitter Statistics: Overall. Retrieved on April 26, 2015 from: http://www.socialbakers.com/twitter

Solo-Anaeto, M. \& Jacobs, B. (2015). Exploring Social Media as Channels for Sustaining African Culture. International Journal of Humanities and Social Science, vol.5:4, pp.37-42.

Vladutescu, S. (2015). Functions of Communication: An Organizational Communication Case. Retrieved from: http://vixra.org/pdf/1601.0201v1.pdf

Wulandari, S. (2014). Speech Act Analysis of Facebook Statuses Used by Students of Muhammadiyah University of Surakarta (Unpublished Masters' Thesis). Surakarta: Muhammadiyah University.

Anmol Ahmad is Lecturer in the Department of Humanities, COMSATS Institute of Information Technology, Islamabad.

Fizza Farrukh is Lecturer in the Department of Humanities, Air University, Islamabad. 